\title{
Psoriasiform Eruption and Worsening of Pustulosis Palmoplantaris After Treatment with Two Anti-TNF- $\alpha$ Inhibitors, Followed by Successful Treatment with Ustekinumab
}

Nathalie A. Bogaards · Menno A. de Rie

Received: July 25, 2016 / Published online: October 25, 2016

(C) The Author(s) 2016. This article is published with open access at Springerlink.com

\begin{abstract}
Introduction: Tumor necrosis factor (TNF)- $\alpha$ inhibitors are widely used for the treatment of inflammatory diseases. One of the side effects of TNF-inhibitors is the development of a psoriatiform eruption, also known as paradoxical psoriasis. In this case report, we describe a patient with this side effect after treatment with adalimumab and etanercept.
\end{abstract}

Case Report: A 45-year-old female was treated with adalimumab $40 \mathrm{mg}$ once every 2 weeks for pustulosis palmoplantaris and psoriatic arthritis. After 2 injections, the patient developed a psoriatiform eruption on her body, which improved after discontinuation of adalimumab but worsened after treatment with etanercept $50 \mathrm{mg}$ twice weekly. Eventually, the patient was treated with topical corticosteroids and ustekinumab $45 \mathrm{mg}$ once every 3 months

Enhanced content To view enhanced content for this article go to http://www.medengine.com/Redeem/ 7F07F0602F04898F.

N. A. Bogaards $(\bowtie) \cdot$ M. A. de Rie

Department of Dermatology, Academic Medical

Center, Amsterdam, The Netherlands

e-mail: nbogaards@hotmail.com with a complete remission of the psoriatiform eruption.

Discussion: Several case reports and reviews have been published in recent years which describe patients with a psoriatiform eruption after treatment with TNF- $\alpha$ inhibitors. The pathogenesis that causes this psoriatic eruption is unclear. In conclusion, we describe a patient with a psoriatiform eruption after treatment with adalimumab and etanercept. This patient had to discontinue the treatment and eventually had a complete response after treatment with topical corticosteroids and treatment with ustekinumab.

Keywords: Anti-TNF- $\alpha$; Adalimumab; Eruption; Etanercept; Paradoxal psoriasis; Psoriasis; Psoriatiform; Ustekinumab

\section{INTRODUCTION}

Tumor necrosis factor (TNF)- $\alpha$ inhibitors have been of great benefit in the treatment of inflammatory diseases, such as Crohn's disease, rheumatoid arthritis, ankylosing spondylitis and psoriasis [1]. With the increased use of TNF- $\alpha$ inhibitors, it is 
important to recognize and understand the cutaneous adverse effects [2]. A number of case reports and case series describe patients who develop psoriasiform eruptions while on TNF- $\alpha$ inhibitors. These eruptions can exist of plaque, pustular or guttate psoriasis. Nail psoriasis has also been seen, with characteristic features of onycholysis, discoloration and pitting. All TNF- $\alpha$ inhibitors including inflixmab, adalimumab and etanercept can be responsible for these reactions [1-4].

In this case report, we describe a patient with pustulosis palmoplantaris, who had worsening of her primary skin disease and developed a generalized psoriasiform eruption after treatment with adalimumab and etanercept.

\section{CASE REPORT}

A 45-year-old woman presented at the outpatient clinic because of disabling skin lesions. On examination, we found erythematous and squamous papules and plaques on her trunks, limbs, palms of her hands, soles of her feet, scalp and dystrophic nails of both hands and feet (Fig. 1). The lesions had started 2 months earlier, after starting treatment with adalimumab $40 \mathrm{mg}$ once every
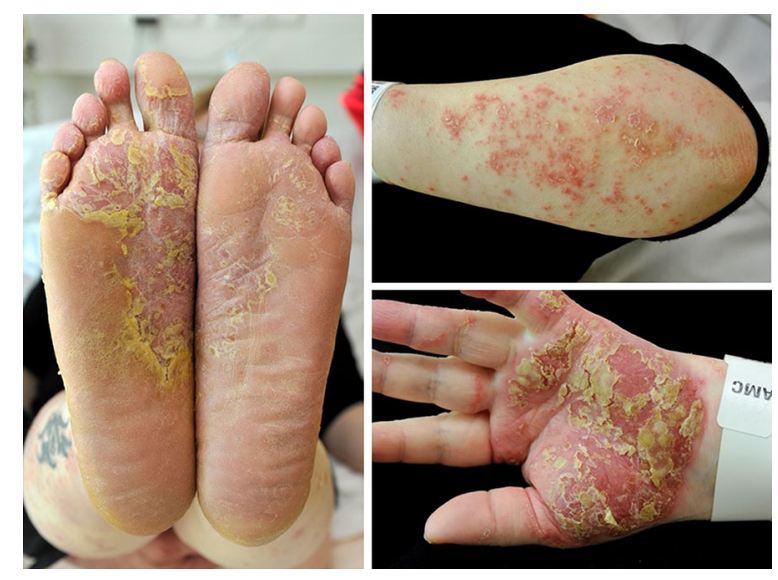

Fig. 1 June 2013, skin lesions after treatment with adalimumab
2 weeks. This patient was known from 7 years before with pustulosis palmoplantaris and psoriatic arthritis. Because of this arthritis, her rheumatologist started treatment with adalimumab. Previous treatments were triamcinolone injections (ineffective), leflunomide (Arava), methotrexate, acitretin, prednisone (all four were stopped because of side effects) and UVB phototherapy.

After the first injection of adalimumab, the patient experienced a positive effect on her pustulosis palmoplantaris, but after the second injection the lesions became worse and an itchy rash started on the rest of her body. She was given topical therapy with potent corticosteroid creams and the treatment with adalimumab was stopped. Despite this, the lesions especially of her hands and feet got worse, leading to immobility, and the patient was therefore admitted to our clinical dermatology ward.

Biopsies were taken from the palm of her hand and from one of the lesions on her arm (Fig. 2). The biopsies showed hyper- and parakeratosis, subcorneal pustels with neutrophilic granulocytes and spongiosis. A perivascular inflammation with extravasation

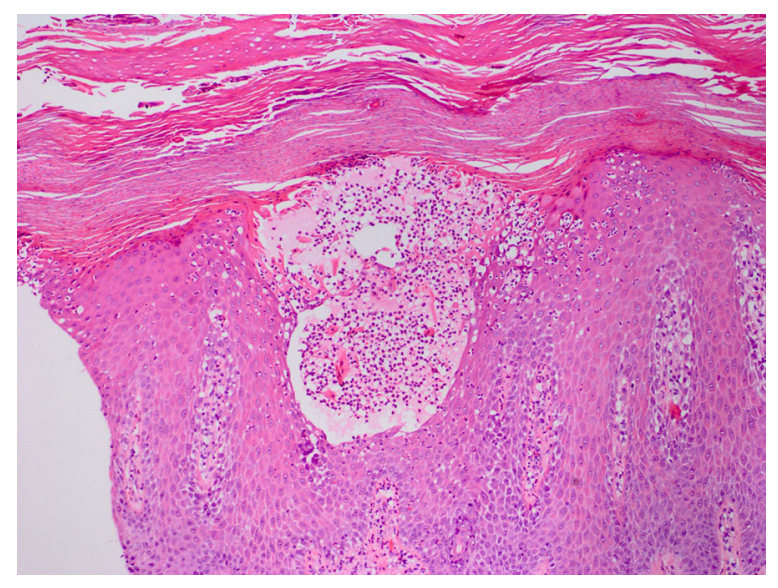

Fig. 2 Skin biopsy shows hyper- and parakeratosis, subcorneal pustels with neutrophilic granulocytes and spongiosis, a perivascular inflammation with extravasation of neutrophilic granulocytes 
of neutrophilic granulocytes was found. A diagnosis of pustulosis palmoplantaris with a psoriatic eruption caused by adalimimab was made.

Blood examination showed a slightly elevated C-reactive protein level and leucocytosis. Antibodies against adalimumab could be detected (95 AE/ml). The adalimumab levels were measured by means of enzyme-linked immunosorbent assay, performed at the Laboratory for Monoclonal Therapeutics, Sanquin Diagnostic Services. The adalimumab blood serum level was $0.1 \mu \mathrm{g} / \mathrm{ml}$.

Treatment was switched to etanercept $50 \mathrm{mg}$ twice weekly in combination with systemic erythromycin $500 \mathrm{mg} 4$ times daily (Figs. 3, 4). After 2 months, this treatment also failed. Methotrexate (which was given in combination with the last therapy) had to be stopped because of subjective side effects.

After discontinuing etanercept treatment and starting treatment with clarithromycin $300 \mathrm{mg}$ three times daily, her skin condition was slowly getting better. The patient was treated in our daycare center multiple days a week with different topical therapies, UVB photo-therapy and multiple antibiotics. The pustulosis palmoplantaris and the psoriatic
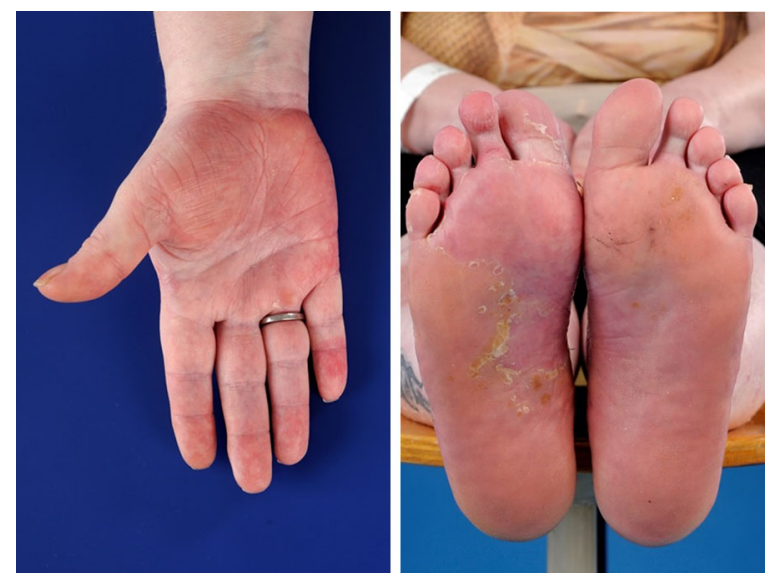

Fig. 3 July 2013, after submission to our clinical ward and treatment with topical corticosteroids and tetracyclins
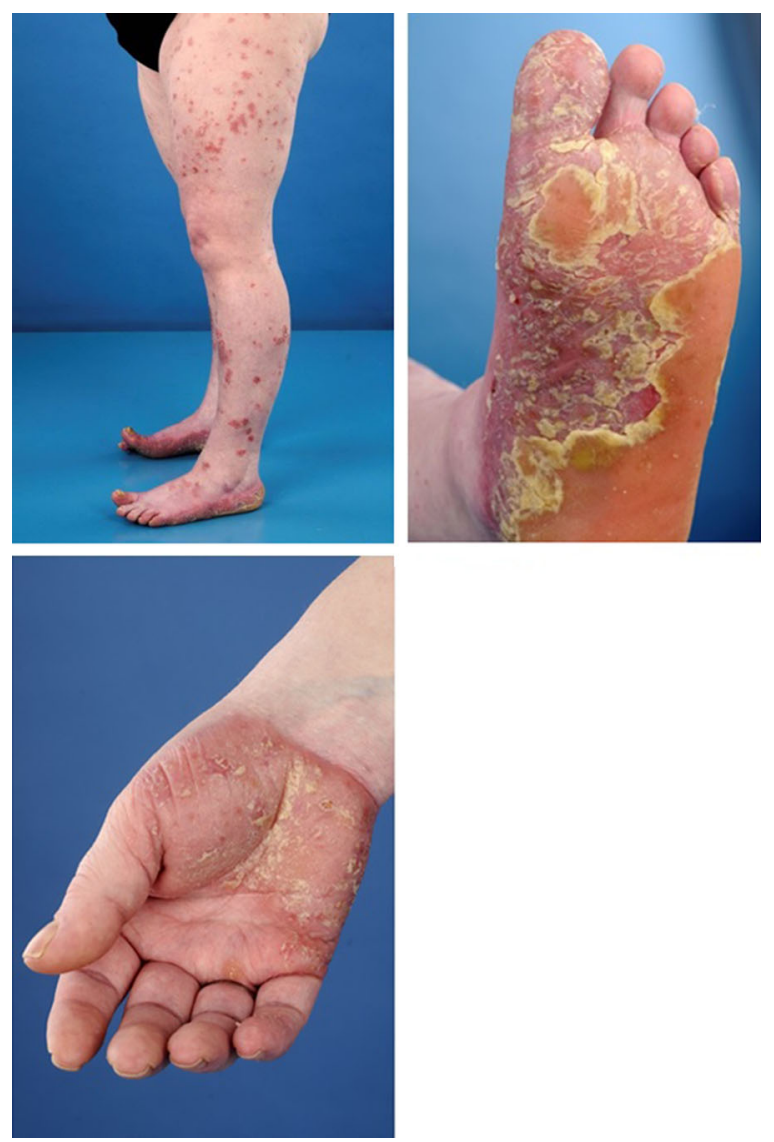

Fig. 4 September 2013, after treatment with etanercept

eruption were slowly getting better. Because of worsening of her psoriatic arthritis, treatment with ustekinumab was started. Eventually, the psoriatic eruption that was started after treatment with adalimumab was gone and the pustulosis palmoplantaris on hands and feet improved.

\section{Compliance with Ethics Guidelines}

Informed consent was obtained from the patient for being included in the study.

\section{DISCUSSION}

Anti-TNF- $\alpha$ therapies are widely used in the treatment of inflammatory disorders, such as 
psoriasis, arthritis and inflammatory bowel diseases. Side effects of these treatments have been reported, including a de novo or worsening of psoriatic eruption. This adverse reaction is also known in the literature as paradoxical psoriasis. Many case reports and case series have been published to describe these patients who use either infliximab, adalimumab or etanercept, with an incidence of 1-5\% [1-4]. In larger case studies, no predisposing factors for paradoxal psoriasis have been described. Only a minority of the patients treated with anti-TNF- $\alpha$ agents had a history of psoriasis or a family member with psoriasis.

In a systematic literature review from 1996 to 2009, 207 patients suffering from paradoxal psoriasis were analyzed. Patients were treated with anti-TNF- $\alpha$ agents for rheumatoid arthritis, seronegative spondylarthropathy, inflammatory bowel disease, psoriasis or others. Patients were treated with either infliximab (59\%), etanercept (19\%) or adalimumab (22\%). The majority of these patients developed plaque-type (50\%), pustular $(56 \%)$ or guttate psoriasis $(12 \%)$. Most patients $(67 \%)$ were able to continue their anti-TNF- $\alpha$ treatment, and $57 \%$ of them had a complete or partial remission of the psoriatic eruption [3].

Another systematic review showed similar results [5]. In patients whose treatment was discontinued, $32 \%$ had a complete remission of the psoriatic eruption. Patients who continued their therapy showed a complete remission of $29 \%$. Of the patients who switched to another anti-TNF- $\alpha$ therapy, $24 \%$ showed a complete remission [5]. Other studies showed no beneficial effect after switching to another anti-TNF- $\alpha$ therapy [2].

Biopsies taken from the psoriatic lesions caused by anti-TNF- $\alpha$ therapies showed in most cases a psoriatiform pattern, but a lichenoid pattern, spongiosis, epidermal edema and neutrophilic infiltration have also been reported [6, 7]. The pathogenesis that causes this psoriatic eruption is unclear. There are some hypotheses that can explain the eruption. MxA (myxoprotein A) is a protein that is induced by interferon (IFN) alpha and beta. Biopsies taken from the psoriatic eruption in patients with TNF- $\alpha$ inhibitors show an increase in this MxA protein in comparison with healthy controls and patients with a psoriasis vulgaris. Anti-TNF- $\alpha$ therapies produce a decrease of TNF- $\alpha$, but can also induce high levels of IFN, which may lead to an increase of MxA protein [6].

IFN- $\alpha$ can also induce an increase of specific receptors, including the chemokine receptor CXCR3. This may lead to an increase of T-cells and neutrophils in the skin, thus mimicking psoriasis. Pro-inflammatory cytokines, induced by IFN- $\alpha$, can stimulate the Th17 pathway, also leading to psoriasis $[8,9]$. This may also explain why ustekinumab, which is a IL23 blocker, has a beneficial effect on this type of psoriatiform eruption.

Recently, Cabaleiro et al. found an association between genetic polymorphism and paradoxal reactions in patients with psoriasis who were treated with anti-TNF- $\alpha$ therapies. Five single-nucleotide polymorphisms were associated [10].

Collamer et al. [11] proposed an algorithm for the treatment of anti-TNF- $\alpha$-induced paradoxical reaction. Depending on the severity of the paradoxical reaction, patients should be treated aggressively with topical corticosteroids, keratolytics and vitamin D analogs and if necessary additionally with ultraviolet phototherapy, methotrexate, acitretin and ciclosporin. For patients who continue to have recalcitrant skin disease, biologic therapy with other than TNF antagonists can be considered. For instance, in 
patients suffering from psoriatic arthritis and Crohn's disease, treatment of paradoxical psoriasis with ustekinumab may be effective [12].

\section{CONCLUSION}

In this case report, we present a patient with a palmoplantar pustulosis and psoriatic arthritis, who developed a psoriatiform eruption after treatment with adalimumab. Different topical and systemic psoriasis treatments did not have a beneficial effect on the psoriatic lesions. Switching to etanercept, another anti-TNF- $\alpha$ treatment, showed a partial response at first, but later this patient developed the same psoriatiform eruption. Treatment with ustekinumab eventually resulted in an almost complete remission of the skin lesions and good control of her psoriatic arthritis.

\section{ACKNOWLEDGEMENTS}

No funding or sponsorship was received for this study or publication of this article. The datasets during and/or analyzed during the current study are available from the corresponding author on reasonable request. All named authors meet the International Committee of Medical Journal Editors (ICMJE) criteria for authorship for this manuscript, take responsibility for the integrity of the work as a whole, and have given final approval for the version to be published. We would like to thank Dr J.R. Mekkes, dermatologist at the Academic Medical Center Amsterdam for his expertise and advisements in the treatment of this patient.

Disclosures. N.A. Bogaards and M.A. de Rie have nothing to disclose.

\section{Compliance with Ethics}

Guidelines. Informed consent was obtained from the patient for being included in the study.

Open Access. This article is distributed under the terms of the Creative Commons Attribution-NonCommercial 4.0 International License (http://creativecommons.org/licenses/ by-nc/4.0/), which permits any noncommercial use, distribution, and reproduction in any medium, provided you give appropriate credit to the original author(s) and the source, provide a link to the Creative Commons license, and indicate if changes were made.

\section{REFERENCES}

1. Wollina U, Hansel G, Koch A, Schönlebe J, Köstler E, Haroske G. Tumor necrosis factor- $\alpha$ inhibitor-induced psoriasis or psoriasiform exanthema. First 120 cases from the literature including a series of six new patients. Am J Clin Dermatol. 2008;9:1-14.

2. Nguyen K, Vleugels RA, Velez NF, Merola JF, Qureshi AA. Psoriasiform reactions to anti-tumor necrosis factor $\alpha$ therapy. J Clin Rheumatol. 2013;19:377-81.

3. Collamer AN, Battafarano DF. Psoriatic skin lesions induced by tumor necrosis factor antagonist therapy: clinical features and possible immunopathogenesis. Semin Arthritis Rheum. 2010;40:233-40.

4. Shmidt E, Wetter DA, Ferguson SB, Pittelkow MR. Psoriasis and palmoplantar pustulosis associated with tumor necrosis factor- $\alpha$ inhibitors: the Mayo Clinic experience, 1998 to 2010. J Am Acad Dermatol. 2011;67:179-85.

5. Denadai R, Teixeira FV, Steinwurz F, Romiti R, Saad-Hossne R. Induction or exacerbation of psoriatic lesions during anti-TNF- $\alpha$ therapy for inflammatory bowel disease: a systematic literature review based on 222 cases. J Crohns Colitis. 2013;7:517-24.

6. Seneschal J, Milpied B, Vergier B, Lepreux S, Schaeverbeke T, Taïeb A. Cytokine imbalance with increased production of interferon-alpha in psoriasiform eruptions associated with antitumour 
necrosis factor-alpha treatments. $\mathrm{Br} \mathrm{J}$ Dermatol. 2009;161:1081-8.

7. Laga AC, Vleugels RA, Qureshi AA, Velazquez EF. Histopathologic spectrum of psoriatiform skin reactions associated tumor necrosis factor- $\alpha$ inhibitor therapy. A study of 16 biopsies. Am J Dermatopathol. 2010;32:568-73.

8. Kip KE, Swoger JM, Grandinetti LM, Barrie AM, Greer JB, Regueiro MD. Tumor necrosis factor $\alpha$ antagonist-associated psoriasis in inflammatory diseases: an analysis of the FDA adverse event reporting system. Inflamm Bowel Dis. 2013;19:1164-72.

9. Friedrich M, Tillack C, Wollenberg A, Schauber J, Brand S. IL-36 $\gamma$ sustains a proinflammatory self-amplifying loop with IL-17C in anti-TNF-induced psoriasiform skin lesions of patients with Crohn's disease. Inflamm Bowel Dis. 2014;20:1891-901.
10. Cabaleiro T, Prieto-Pérez R, Navarro R, Solano G, Román M, Ochoa D, Abad-Santos F, Daudén E. Paradoxical psoriasiform reactions to anti-TNF $\alpha$ drugs are associated with genetic polymorphisms in patients with psoriasis. Pharmacogenomics J. 2016;16:336-40.

11. Collamer AN, Guerrero KT, Henning JS, Battafarano DF. Psoriatic skin lesions induced by tumor necrosis factor antagonist therapy: a literature review and potential mechanisms of action. Arthritis Rheum. 2008;59:996-1001.

12. Puig L, Morales-Múnera CE, López-Ferrer A, Geli C. Ustekinumab treatment of TNF antagonist-induced paradoxical psoriasis flare in a patient with psoriatic arthritis: case report and review. Dermatology. 2012;225:14-7. 